\title{
Economic evaluation of sublingual immunotherapy vs symptomatic treatment in allergic asthma
}

Renato Ariano, MD*; Patrizia Berto, Pharm D†; Cristoforo Incorvaia, MD ; Giuseppe Di Cara, MD\$; Rachele Boccardo, MD§; Stefania La Grutta, MD\|; Paola Puccinelli, Pharm DI; and Franco Frati, MD§I

Background: The worldwide increased prevalence of allergic diseases, and especially of respiratory allergy, is paralleled by increased health costs. This requires consideration of the cost to efficacy ratio of the available treatment to identify the optimal choice.

Objective: To compare the different economic relevance, over a long evaluation time, of symptomatic pharmacologic therapy and sublingual immunotherapy (SLIT) in patients with allergic asthma.

Methods: Seventy patients with perennial allergic asthma, sensitized to dust mites, were enrolled; 50 of these patients were treated with SLIT against house dust mites and 20 were treated with symptomatic drugs. The patients were evaluated for 2 years after discontinuing immunotherapy, which was performed for 3 years, to obtain a more complete follow-up. Symptom scores, medication scores, and all other direct medical costs were evaluated with a specific questionnaire.

Results: Patients treated with SLIT plus drugs had a higher mean annual cost in the first year of SLIT treatment compared with patients only receiving drug treatment, but the mean annual cost became significantly lower since the end of SLIT both in the whole population and in the subgroups defined by disease severity.

Conclusion: The economic advantage measured alongside this prospective observational study was long lasting and still present at the fifth year of the follow-up ( 2 years after discontinuing SLIT) and could positively be related to the persistent good clinical control of patients.

\section{INTRODUCTION}

The worldwide increased prevalence of allergic diseases, and especially of respiratory allergy, is well-known ${ }^{1}$ and is associated with an increase of health costs, ${ }^{2-9}$ which is clearly recognized by the National Healthcare System (NHS). Considering that the economical aspects have an impact on health status and treatment choices, physicians and prescribers are increasingly asked to take into account the cost-effectiveness ratio of every medical treatment, to identify the most efficient solutions to improve patient's health status while balancing the management of health cost.

This is especially important for new emerging therapies for allergy, such as specific sublingual immunotherapy (SLIT). The clinical efficacy of SLIT is clearly demonstrated in a number of studies by using scores measuring clinical symp-

Affiliations: * Internal Medicine Department, Ospedale di Bordighera Azienda Sanitaria Locale 1, Imperia, Italy; $†$ Pbe Consulting, Verona, Italy; $\ddagger$ Allergy/Pulmonary Rehabilitation, Istituti Clinici di Perfezionamento Hospital, Milan, Italy; § Institute of Pediatrics, Department of Medical and Surgical Specialty and Public Health, Perugia, Italy; \|Environment and Health, Istituto di Biologia Molecolare, Consiglio Nazionale delle Ricerche, Agenzia Regionale Protezione Ambientale, Sicilia, Palermo, Italy; II Medical and Scientific Department, Stallergenes, Milan, Italy.

Disclosures: Drs Berto and Incorvaia are scientific consultants for Stallergenes Italy.

Received for publication December 19, 2008; Received in revised form March 22, 2009; Accepted for publication April 1, 2009.

Ann Allergy Asthma Immunol. 2009;103:254-259.

toms and drug intake. ${ }^{10-12}$ In particular, several studies have shown a significant reduction of drug use during SLIT, both in allergic rhinitis and in asthma, ${ }^{11}$ but did not consider the advantage in terms of costs.

Specifically addressed pharmacoeconomic studies on subcutaneous immunotherapy (SCIT) in patients with rhinitis and asthma have been available since the mid-1990s ${ }^{13-21}$; recently, some studies, mostly conducted on patients with seasonal allergy, also analyzed the effects of SLIT on health expenditures. ${ }^{22-25}$

The aim of the present study was to estimate, during a long period, the economic value of symptomatic drug therapy and SLIT in adult patients with rhinitis and asthma, sensitized to house dust mites. The main goal of the study was to evaluate the effectiveness and the use of health resources for SLIT vs drug therapy during a 5-year follow-up (3 years of SLIT and 2 years after its discontinuation). A secondary goal was to evaluate the efficacy and tolerability of SLIT.

\section{METHODS}

\section{Patients}

Seventy patients from the Allergy Center of Bordighera Hospital, Bordighera, Italy, were enrolled in the study. All patients had allergic rhinitis and allergic asthma, with a level of 1 to 3 according to the Global Strategy for Asthma Management and Prevention classification, ${ }^{26}$ and were sensitized to house dust mites. Patients were randomized by the program 
(detailed at http://www.randomization.com) into 2 groups: 20 were treated only with symptomatic drugs (group 1), and 50 were treated with SLIT to house dust mites plus drugs as needed (group 2). This proportion was chosen to minimize the number of patients receiving the less favorable treatment while maintaining a sufficient number for statistical analysis. The inclusion criteria were as follows: age of 8 to 50 years, persistent allergic asthma for at least 2 years, skin prick test result positive to Dermatophagoides (wheal diameter $>5$ $\mathrm{mm}$ ), and positive radioallergosorbent test result for Dermatophagoides (at least class 2). Exclusion criteria were as follows: systemic immunological disease, congenital immunodeficiency, severe systemic disease, neoplastic diseases, severe psychological or neurologic disorders, treatment with SCIT or SLIT in the preceding 5 years, treatment with systemic steroids or $\beta$-blockers, pregnancy or lactation, and sensitization to other perennial or prolonged seasonal allergens (such as Parietaria pollen) able to interfere with the study. Sensitization to pollens with a short seasonal duration in our area, such as cypress (11 patients), olive (10 patients), Betulaceae (9 patients), mugwort (6 patients), and beech (4 patients), was not an exclusion criterion.

The study was approved by the Ethical Committee of Bordighera Hospital, and all patients gave their informed consent to the study.

\section{Study Design}

The study was prospective: at visit 1, the patients were evaluated and included in the study; at visit 2 , the randomization and the start of SLIT, with delivery of clinical diaries, were scheduled. Further visits every 6 months, with evaluation of clinical diaries, were performed. After discontinuing SLIT, the visits were every 6 months, with accurate checking of clinical diaries, but the mean costs were evaluated on an annual basis to the purpose of the study. Patients included in the SLIT group were treated for at least 3 years. The study was performed between January 2002 and December 2006 and lasted for 2 years after discontinuing SLIT, with an annual follow-up. Score cards were used to collect symptoms and costs (ie, resources consumed). Symptom scores were coded as follows: 0, no symptoms; 1, mild symptoms; 2, moderate symptoms; and 3, severe symptoms. The drug intake score was measured, attributing 1 point for each administration. The cost was calculated, at each follow-up visit, by the general practitioner or the specialists and by the number of drug boxes purchased. The mean annual cost per patient was the sum of visits, specialist's testing (such as spirometry and skin prick tests), specific immunotherapy, and all drugs related to asthma treatment drugs (at NHS charge). Patients could purchase the drugs allowed during the study in any pharmacy, the price being the same because in Italy it is under government control. Each resource or drug was assigned a unitary cost, according to the actual NHS rate lists ${ }^{27}$ or market prices. ${ }^{28}$

\section{Treatment}

The extract used for SLIT was a mix of Dermatophagoides pteronyssinus and Dermatophagoides farinae (Staloral300; Stallergenes, Antony, France), standardized in the index of reactivity. SLIT was performed by the up dosing schedule suggested by the manufacturer, with a top dose of 300 in the index of reactivity, and subsequent maintenance treatment was performed by administering this dose 3 days a week. The consumption of allergen extracts was estimated at each visit by the returned boxes.

The agents to be used as needed for drug treatment in the control group or in association with SLIT in the study group were as follows: cetirizine (capsules or drops); spaglumic acid (eyedrops); oximetazoline (nasal spray); fluticasone (topical nasal or bronchial agent); nedocromil (topical nasal or bronchial agent); inhaled budesonide, albuterol, salmeterol, formoterol, and oxitropium; methylprednisolone (capsules or injection); betamethasone (capsules or injection); and theophylline (capsules).

For treatment evaluation, according to the objectives of the study, the variables were defined as follows:

1. Evaluation of clinical efficacy: symptom scores from patient diary (mean of the month before the visit).

2. Pharmacoeconomic evaluation: total cost per patient per year, according to data from the patient's cards and diaries.

3. Patient's evaluation: visual analog scale (VAS) administered at baseline (T0) and at the end of treatment after 3 years (T3).

4. Evaluation of safety and tolerability. All events during SLIT were classified as follows: 0 , absent; 1 , local reaction (ie, local pruritus or edema); 2 , mild systemic reaction (ie, rhinitis or conjunctivitis); and 3, systemic reaction (urticaria, asthma, Quincke edema, or anaphylaxis).

\section{RESULTS}

Table 1 describes patient demographics at T0. The 2 groups were homogeneous for age and basal symptom scores. During the study, 3 patients in group 1 (treated only with drugs), 1 after 1 year and 2 after 2 years, and 2 patients in group 2 (treated with SLIT plus drugs), 1 after 1 year and 1 after 2 years, withdrew from the study for reasons unrelated to treatment. In particular, 2 patients moved to other towns, 2 had family problems, and 1 refused to continue without giving an explanation. Data from patients' cards and diaries were missing in $4(4.0 \%)$ of 100 group 1 patients and in 13

Table 1. Demographic Data at Baseline

\begin{tabular}{llc}
\hline \multicolumn{1}{c}{ Category } & $\begin{array}{c}\text { SLIT plus } \\
\text { drugs }\end{array}$ & Drugs only \\
\hline $\begin{array}{l}\text { Sex, No. (\%) } \\
\text { Male }\end{array}$ & $27(54)$ & $8(40)$ \\
$\quad$ Female & $23(46)$ & $12(60)$ \\
Age, mean (SD), y & $27.98(12.89)$ & $28.20(11.75)$ \\
Symptom score, mean (SD) & $14.00(3.56)$ & $13.70(4.04)$ \\
\hline
\end{tabular}

Abbreviation: SLIT, sublingual immunotherapy. 
(5.2\%) of 250 group 2 patients; this difference was not significant. The comparison between groups at $\mathrm{T} 0$ and at $\mathrm{T} 3$ is shown in Figure 1. At T0, there was no significant difference between group 1 and group 2, whereas at T3, those treated with SLIT had significantly lower scores for each indicator. Furthermore, a statistically significant difference for bronchial, nasal, and total symptom scores was detected between T0 and T3 in group 2, but not in group 1.

The mean patient cost per year for the whole studied population is reported in Figure 2. Patients in group 2 (SLIT plus drugs) had a significantly higher mean annual cost only in the first year of treatment compared with patients in group 1. At year 2, there was no difference; and at year 3, the mean annual cost per patient was insignificantly lower in group 2 . At years 4 and 5, the mean annual cost per patient was significantly lower in group 2 when compared with group 1 (Fig 2).

When the incremental annual costs per patient were estimated for the asthmatic patients (Table 2), the total cost at year 5 of $€ 3.881$ for those treated with SLIT plus drugs represented a $22.7 \%$ savings with regard to the total cost at year 5 of $€ 5.020$ for those treated with drugs only. Such savings tended to increase with disease severity, reaching a value of $33.8 \%$ for severe asthmatic patients.

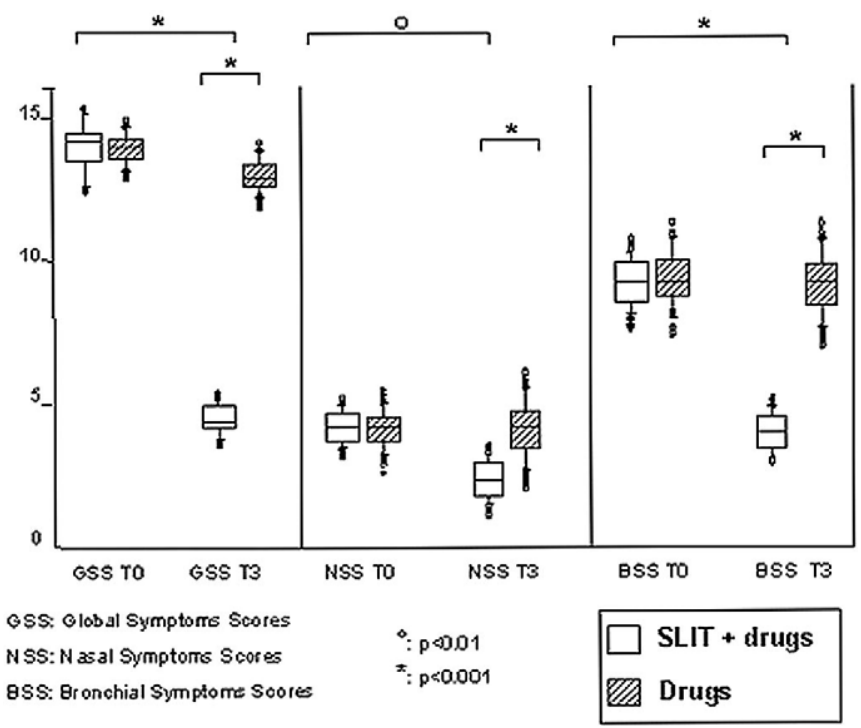

Figure 1. Evaluation of clinical efficacy (symptom score groups before and after sublingual immunotherapy [SLIT]). The comparison between group 1 (treated only with drugs) and group 2 (treated with SLIT plus drugs) at baseline (T0) and after 3 years of SLIT (T3) is shown. There was no significant difference between the 2 groups at T0. There was a statistically significant difference for bronchial, nasal, and global symptom scores (BSS, NSS, and GSS, respectively) between T0 and T3 in group 2 . This difference is significant both in the intragroup analysis (T0 vs T3 for group 2) and in the intergroup analysis (T3 vs T3 for group 2 vs group 1 ). ${ }^{\circ} P<.01$ and $* P<$ .001 (differences among groups were computed by Mann-Whitney test for independent groups).

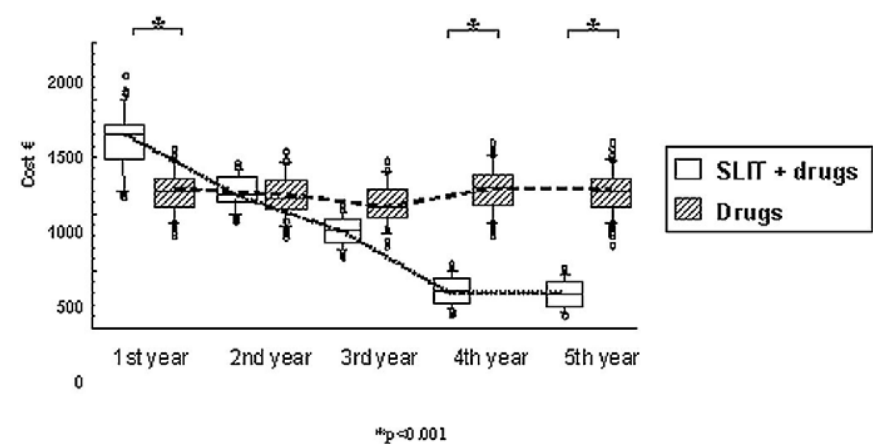

Figure 2. Mean patient cost per year considering the whole studied population. Comparison of mean annual cost in the 5 years of treatment between group 1 (treated only with drugs) and group 2 (treated with sublingual immunotherapy [SLIT] plus drugs). Patients of group 2 (SLIT plus drugs) had a significantly higher mean annual cost in the first year of treatment with SLIT compared with patients of group 1, then the mean annual cost per patient decreased and became significantly lower after the end of SLIT. * $P<.001$ (differences among groups were computed by Mann-Whitney test for independent groups).

The evaluation of the efficacy of the intervention, through VAS scores, is reported in Table 3. At T0, the study and control groups did not differ by VAS score. Patients treated with SLIT plus drugs had a statistically significant reduction in their mean VAS score $(-67.5 \%)$ between T0 and T3. At T3, their mean VAS score was significantly lower than that of patients treated only with drugs. The patients treated only with drugs did not show any significant trend with time.

The use of allergen extracts, as evaluated by checking the returned boxes, was regular in all patients. Adverse reactions in the SLIT-treated group were mild and transient, with 5 class 1 reactions (local itch or edema) and 3 class 2 reactions (rhinitis or conjunctivitis) in 5 patients; the other 45 patients had no adverse events.

\section{DISCUSSION}

The main health outcome of the present study on patients with dust mite-induced rhinitis and asthma is the significant reduction of symptom scores after 3 years of SLIT. Along the same lines, the patients' evaluation of treatment by VAS was undoubtedly more favorable in the SLIT group when compared with the drug-only group. Indeed, it is known that the VAS score is correlated to symptom severity both in adults and children ${ }^{29}$ and to more complex and demanding tools, such as Juniper's quality of life questionnaires. ${ }^{21}$

From the pharmacoeconomic point of view, the total annual cost evaluation for the first 2 years was higher in patients treated with SLIT plus symptomatic drugs, but since the third year of treatment, this trend was reversed, with a higher cost for patients treated only with drugs. Such an advantage increased after the third year, at the end of SLIT treatment, because the cost of SLIT itself was no longer present, whereas its clinical benefits persisted for at least another 2 years (which was the total follow-up of the study). 
Table 2. Incremental Annual Cost Throughout 5 Years for Asthmatic Patients, by Severity

\begin{tabular}{|c|c|c|c|c|c|c|}
\hline \multirow{2}{*}{ Group } & \multicolumn{5}{|c|}{ Yeara } & \multirow{2}{*}{ Change at year $5, \%$} \\
\hline & 1 & 2 & 3 & 4 & 5 & \\
\hline \multicolumn{7}{|l|}{ Total } \\
\hline SLIT plus drugs $(n=50)$ & $1.532(49)$ & $2.584(48)$ & $3.353(48)$ & $3.629(48)$ & $3.881(48)$ & \multirow{2}{*}{-22.7} \\
\hline Drugs only $(n=20)$ & $1.008(19)$ & $2.012(17)$ & $3.001(17)$ & $4.012(17)$ & $5.020(17)$ & \\
\hline \multicolumn{7}{|l|}{ Asthma 1} \\
\hline SLIT plus drugs $(n=20)$ & $1.239(19)$ & $2.097(19)$ & $2.825(19)$ & $3.083(19)$ & $3.326(19)$ & \multirow[b]{2}{*}{-9.5} \\
\hline Drugs only $(n=10)$ & $735(9)$ & $1.469(8)$ & $2.204(8)$ & $2.943(8)$ & $3.675(8)$ & \\
\hline \multicolumn{7}{|l|}{ Asthma 2} \\
\hline SLIT plus drugs $(n=12)$ & $1.529(12)$ & $2.546(11)$ & $3.317(11)$ & $3.600(11)$ & $3.859(11)$ & \multirow[b]{2}{*}{-28.9} \\
\hline Drugs only $(n=5)$ & $1.068(5)$ & $2.154(4)$ & $3.222(4)$ & $4.332(4)$ & $5.424(4)$ & \\
\hline \multicolumn{7}{|l|}{ Asthma 3} \\
\hline SLIT plus drugs $(n=18)$ & $2.025(18)$ & $3.451(18)$ & $4.284(18)$ & $4.582(18)$ & $4.841(18)$ & \multirow[b]{2}{*}{-33.8} \\
\hline Drugs only $(n=5)$ & $1.494(5)$ & $2.956(5)$ & $4.374(5)$ & $5.830(5)$ & $7.310(5)$ & \\
\hline
\end{tabular}

Abbreviation: SLIT, sublingual immunotherapy.

${ }^{a}$ All costs are given in Euros. Numbers in parentheses indicate the number of patients at each time point.

Table 3. Patient's Global Evaluation (VAS Score)

\begin{tabular}{cccc}
\hline Variable & $\begin{array}{c}\text { SLIT plus drugs } \\
(\mathbf{n = 5 0 )}\end{array}$ & $\begin{array}{c}\text { Drugs only } \\
(\mathbf{n = 2 0 )}\end{array}$ & $\boldsymbol{P}$ value $^{\mathrm{a}}$ \\
\hline VAS score & & & \\
At baseline & $7.38(1.12)$ & $7.75(1.07)$ & .77 \\
After 3 y & $2.40(1.81)$ & $6.35(1.81)$ & $<.001$ \\
$P$ value $^{\mathrm{a}}$ & $<.001$ & .45 & $\mathrm{NA}$ \\
\hline
\end{tabular}

Abbreviations: NA, not applicable; SLIT, sublingual immunotherapy; VAS, visual analog scale.

aObtained via Mann-Whitney test for independent groups.

Although pharmacoeconomic studies focusing on SLIT are still few, recent data have underlined the usefulness of this approach's strategy in the global long-term care of patients and health care service. ${ }^{30}$ Our current results show a substantial reduction in all outcome measures during SLIT compared with the previous period. Similarly, in a population sample of 135 children with asthma, rhinitis, and/or conjunctivitis, ${ }^{22}$ there was a positive effect on all the clinical variables evaluated as outcome measures (number of exacerbations, visits, and absence from nursery or school) and also on the direct costs (Euros spent on drugs, specialists' visits, and SLIT) and indirect costs (costs resulting from children's school and parental work loss). The average annual cost per patient was $€ 2,672$ before SLIT initiation and $€ 629$ during SLIT. Furthermore, in the asthma subanalysis involving 41 children with SLIT and 35 controls, a substantial reduction in cost in SLIT-treated children was shown; similar results were also found for allergen subgroups.

In the Sublingual Immunotherapy Pollen Allergy Italy Study, the positive influence of SLIT was evaluated in adult patients, based on an epidemiologic model supported by data on the use of resources and health status transitions, from 25 centers and 2,200 Italian patients. ${ }^{23}$ This study confirmed that SLIT is more effective (both in terms of clinical improvement and lesser disease worsening) and less expensive than symp- tomatic therapy. ${ }^{23}$ In the Sublingual Immunotherapy in Allergic Patients study, a prospective observational study, performed on 382 patients allergic to grass pollen, after the first year of SLIT, there were cost decreases for symptomatic treatment of $22 \%$ in patients with rhinitis and of $34 \%$ in patients with rhinitis and asthma. ${ }^{24}$

The economic aspects of SLIT have also been evaluated in 2 recent SLIT studies performed with oral tablets for grass pollen in northern Europe ${ }^{31}$ and southern Europe ${ }^{32}$ In the first study, a societal perspective was adopted, and the evaluation of cost-effectiveness of SLIT compared with use of symptomatic drugs in a 9-year time horizon analysis was performed in 7 northern European countries. ${ }^{31}$ In this study, the main outcome measure was quality-adjusted life years as an index of health-related quality of life, whereas we used a simpler measure (VAS, recently validated in its evaluation capacity), ${ }^{29}$ but the 2 pharmacoeconomic evaluations are in agreement. In fact, our data support the cost-effective evidence that SLIT is better than symptomatic treatment, either producing statistically significant differences for all efficacy end points or reducing the annual cost. Interestingly, our results shown in Figure 2 point out the lowest annual price of SLIT treatment, corresponding to $€ 1.532$ ( \pm 333.8$)$ and $€ 769.1$ ( \pm 74.83$)$ in the first and third years, respectively, compared with an annual price of $€ 1,550$ to $€ 1,900$ found in a prospective pharmacoeconomic analysis of the tablet SLIT preparation in patients with grass pollen-associated rhinitis living in 4 southern European countries (Spain, France, Italy, and Austria). ${ }^{32}$

Our results are very close to those of a study recently conducted in France concerning a cost-efficacy analysis on the comparison of immunotherapy (subcutaneous and sublingual) and current symptomatic treatment in adults and children with dust mite and pollen allergy. ${ }^{25}$ As expected, SLIT, because of no need of visits for injections, yielded a higher cost savings with regard not only to SCIT but also to drugs, especially in pollen-allergic patients (both adults and chil- 
dren). From all of these studies, it is apparent that there is an economic advantage of SLIT over standard drug treatment; however, our results add relevant information to the economic evaluation of SLIT because they derive from an observational study on a population of adults sensitized to perennial allergens. In addition, in the present study, we also found, both in the intragroup and intergroup analyses, a statistically significant difference for bronchial, nasal, and total symptom scores between $\mathrm{T} 0$ and $\mathrm{T} 3$ in patients treated with SLIT plus drugs, confirming once more the clinical efficacy of SLIT. The latter results are consistent with previous studies demonstrating the improvement effect of SLIT on clinical symptoms. In particular, in the SLIT plus drugs group, the significant bronchial symptom score reduction brings evidence to the hypothesis that SLIT could be effective on upper and lower respiratory tract symptom control in patients with asthma and rhinitis.

Even more important is the observation concerning the breakeven point for SLIT plus drugs strategy, in relation to the severity of disease, which highlights the significant savings of health care resources in patients with severe disease (ie, patients who usually generate the higher health costs). ${ }^{33}$

The safety and tolerability of SLIT are well-known, ${ }^{34}$ but in our study they were particularly good: 43 (90\%) of 48 treated patients had no adverse events and no severe reactions. The relationship between safety and cost is unexplored, but one may argue that adverse reactions, considering their influence on patient's management, including more drugs, more visits, and schedule modification, are a factor to include in future investigations.

In conclusion, SLIT, along with an improvement of symptom scores and drug intake scores, effectively produces a reduction of total annual costs in asthmatic patients, from the third year of therapy. Not surprisingly, in the SLIT plus drugs arm of our study, the cost of SLIT and the need to maintain symptomatic drug treatment cause an increase of the total annual patient cost during the first 2 years. However, the reduction of costs from the third year on is relevant and persists for at least 2 years after discontinuing SLIT.

\section{ACKNOWLEDGMENT}

We thank Giovanni Viegi, MD, for his advice.

\section{REFERENCES}

1. The International Study of Asthma and Allergies in Childhood (ISAAC) Steering Committee. Worldwide variation in prevalence of symptoms of asthma, allergic rhinoconjunctivitis, and atopic eczema. Lancet. 1998; 351:1225-1232.

2. Upton MN, McConnachie A, McSharry C, et al. Intergenerational 20 year trends in the prevalence of asthma and hay fever in adults: the Midspan family study survey of parents and offspring. BMJ. 2000;321: $88-92$.

3. Mackowiak JI. The health and economic impact of rhinitis. Am J Manag Care. 1997;3:S8-S18.

4. Law AW, Reed SD, Sundy J, et al. Direct costs of allergic rhinitis in the United States: estimates from the 1996 Medical Expenditure Panel Survey. J Allergy Clin Immunol. 2003;111:296-300.

5. Reed SD, Lee TA, McCrory DC. The economic burden of allergic rhinitis. Pharmacoeconomics. 2004;22:345-361.

6. Schramm B, Ehlken B, Smala A, et al. Cost of illness of atopic asthma and seasonal allergic rhinitis in Germany: 1-year retrospective study. Eur Respir J. 2003;21:116-122.

7. O'Connell EJ. The burden of atopy and asthma in children. Allergy. 2004;59(suppl 78):7-11.

8. Weiss KB, Sullivan SD. The health and economics of asthma and rhinitis, I: assessing the economic impact. J Allergy Clin Immunol. 2001;107:3-8.

9. Cisternas MG, Blanc PD, Yen IH, et al. A comprehensive study of the direct and indirect costs of adult asthma. J Allergy Clin Immunol. 2003;111:1212-1218.

10. WHO Position Paper. Allergen immunotherapy: therapeutic vaccines for allergic diseases. Allergy. 1998;53:11-18.

11. Wilson DR, Torres-Lima M, Durham SR. Sublingual immunotherapy for allergic rhinitis: systematic review and meta-analysis. Allergy. 2005; 60:4-12.

12. Passalacqua G, Valovirta E, van Weissenbruch R, Frati F, Incorvaia C, Puccinelli P. Sublingual Specific Immunotherapy: From Scientific Background to Clinical Practice. Milan, Italy: Sinergie; 2007.

13. Buchner K, Siepe M. Nutzen der Hyposensibilierung unter wirtschaftlichen Aspekten. Allergo J. 1995;4:156-163.

14. Fischer P. Therapie des allergisches Asthma: Die spezifische Hyposensibilierung kann helfen Kosten in Milliardenhohe einzusparen. Laryngorhinootologie. 1995;74:28.

15. Kumar P, Kamboj S, Rao P, et al. The cost of acre and quality of life in patients with allergic rhinitis on allergen immunotherapy. Allergy Clin Immunol Int. 1997;9:133-135.

16. Creticos PS, Reed CE, Norman PS, et al. Ragweed immunotherapy in adult asthma. N Engl J Med. 1996;334:501-506.

17. Donohue J, Greneider DK, Connor-Lake L, et al. Utilization and cost of immunotherapy for allergic asthma and rhinitis. Ann Allergy Asthma Immunol. 1999;82:339-347.

18. Schadlich PK, Brecht JG. Economic evaluation of specific immunotherapy versus symptomatic treatment of allergic rhinitis in Germany. Pharmacoeconomics. 2000;17:37-52.

19. Le Pen C, Rumeau-Pichen C, Lillin H. L'impact de l'immunothérapie specifique sur le couts directs de la maladie allergique: une etude pragmatique. Rev Francaise d'Allergologie et d'Immunologie Clin. 1997;37:11-14.

20. Petersen KD, Gyrd-Hansen D, Dahl R. Health-economic analyses of subcutaneous specific immunotherapy for grass pollen and mite allergy. Allergol Immunopathol (Madr). 2005;33:296-302.

21. Ariano R, Berto P, Tracci D, et al. Pharmacoeconomics of allergen immunotherapy compared with symptomatic drug treatment in patients with allergic rhinitis and asthma. Allergy Asthma Proc. 2006;27: $159-163$.

22. Berto P, Bassi M, Incorvaia C, et al. Cost effectiveness of sublingual immunotherapy in children with allergic rhinitis and asthma. Eur Ann Allergy Clin Immunol. 2005;37:303-308.

23. Berto P, Passalacqua G, Crimi N, et al. Economic evaluation of sublingual immunotherapy vs symptomatic treatment in adults with polleninduced respiratory allergy: the Sublingual Immunotherapy Pollen Allergy Italy (SPAI) Study. Ann Allergy Asthma Immunol. 2006;97: 615-621.

24. Berto P, Frati F, Incorvaia C, et al. Comparison of costs of sublingual immunotherapy and drug treatment in grass pollen-induced allergy: results from the SIMAP database study. Curr Med Res Opin. 2008;24: 261-266.

25. Omnes LF, Bousquet J, Scheinmann P, et al. Pharmacoeconomic assessment of specific immunotherapy versus current symptomatic treatment for allergic rhinitis and asthma in France. Eur Ann Allergy Clin Immunol. 2007;39:148-156.

26. GINA Workshop Report: Global Strategy for Asthma Management and Prevention. 2002. NIH publication 02-3659.

27. Ministero della Sanità. Nomenclatore Tariffario delle prestazioni ambulatoriali DM 22.7.96. Gazzetta Ufficiale. September 14, 1996:16.

28. Informatore Farmaceutico: Annuario Italiano dei Medicinali e dei 
Laboratori. Milan, Italy: Edizioni OEMF International sri; 2006.

29. Bousquet PJ, Combescure C, Neukirch F, et al. Visual analog scales can assess the severity of rhinitis graded according to ARIA guidelines. Allergy. 2007;62:367-372.

30. Berto P, Frati F, Incorvaia C. Economic studies of immunotherapy: a review. Curr Opin Allergy Clin Immunol. 2008;8:585-589.

31. Bachert C, Vestenbaek U, Christensen J, Griffiths UK, Poulsen PB. Cost-effectiveness of grass allergen tablet (GRAZAX) for the prevention of seasonal grass pollen-induced rhinoconjunctivitis: a northern European perspective. Clin Exp Allergy. 2007;37:772-779.

32. Canonica GW, Poulsen PB, Vestenbaek U. Cost-effectiveness of GRAZAX for prevention of grass pollen-induced rhinoconjunctivitis in southern Europe. Respir Med. 2007;101:1885-1894.

33. Dal Negro R, Berto P, Tognella S, Quareni L; Global Outcomes in Lung
Disease Study Group. Cost-of-illness of lung disease in the TriVeneto Region, Italy: the GOLD Study. Monaldi Arch Chest Dis. 2002;57:3-9.

34. Gidaro G, Marcucci F, Sensi L, Incorvaia C, Frati F, Ciprandi G. The safety of sublingual-swallow immunotherapy: an analysis of published studies. Clin Exp Allergy. 2005;35:565-571.

Requests for reprints should be addressed to:

Franco Frati, $M D$

Scientific and Medical Department

Stallergenes Italia

Via Traiano 7

Milan, Italy

E-mail: frati.f@stallergenes.it 